\title{
Article \\ Glycosyltransferase B4GALNT2 as a Predictor of Good Prognosis in Colon Cancer: Lessons from Databases
}

\author{
Michela Pucci, Nadia Malagolini and Fabio Dall'Olio *(D) \\ Department of Experimental, Diagnostic and Specialty Medicine (DIMES), General Pathology Building, \\ University of Bologna, Via San Giacomo 14, 40126 Bologna, Italy; michela.pucci3@unibo.it (M.P.); \\ nadia.malagolini@unibo.it (N.M.) \\ * Correspondence: fabio.dallolio@unibo.it; Tel.: +39-051-2094704
}

check for updates

Citation: Pucci, M.; Malagolini, N.; Dall'Olio, F. Glycosyltransferase B4GALNT2 as a Predictor of Good Prognosis in Colon Cancer: Lessons from Databases. Int. J. Mol. Sci. 2021, 22, 4331. https://doi.org/10.3390/ ijms22094331

Academic Editor: Takeshi Sato

Received: 30 March 2021

Accepted: 19 April 2021

Published: 21 April 2021

Publisher's Note: MDPI stays neutral with regard to jurisdictional claims in published maps and institutional affiliations.

Copyright: (c) 2021 by the authors. Licensee MDPI, Basel, Switzerland. This article is an open access article distributed under the terms and conditions of the Creative Commons Attribution (CC BY) license (https:// creativecommons.org/licenses/by/ $4.0 /)$.

\begin{abstract}
Background: glycosyltransferase B4GALNT2 and its cognate carbohydrate antigen Sd are highly expressed in normal colon but strongly downregulated in colorectal carcinoma (CRC). We previously showed that CRC patients expressing higher B4GALNT2 mRNA levels displayed longer survival. Forced B4GALNT2 expression reduced the malignancy and stemness of colon cancer cells. Methods: Kaplan-Meier survival curves were determined in "The Cancer Genome Atlas" (TCGA) COAD cohort for several glycosyltransferases, oncogenes, and tumor suppressor genes. Whole expression data of coding genes as well as miRNA and methylation data for B4GALNT2 were downloaded from TCGA. Results: the prognostic potential of B4GALNT2 was the best among the glycosyltransferases tested and better than that of many oncogenes and tumor suppressor genes; high B4GALNT2 expression was associated with a lower malignancy gene expression profile; differential methylation of an intronic B4GALNT2 gene position and miR-204-5p expression play major roles in B4GALNT2 regulation. Conclusions: high B4GALNT2 expression is a strong predictor of good prognosis in CRC as a part of a wider molecular signature that includes ZG16, ITLN1, BEST2, and GUCA2B. Differential DNA methylation and miRNA expression contribute to regulating B4GALNT2 expression during colorectal carcinogenesis.
\end{abstract}

Keywords: glycosylation; colon cancer; $\mathrm{Sd}^{\mathrm{a}}$ antigen; glycosyltransferases; epigenetic regulation

\section{Introduction}

Glycosylation plays a crucial role in a variety of biological processes, including intracellular transport, cell adhesion, cell growth, and apoptotic death [1]. In cancer, glycosylation changes consist of up- or downregulation of numerous carbohydrate structures affecting tumor invasion and progression [2-4]. The $\mathrm{Sd}^{\mathrm{a}}$ antigen is a carbohydrate structure expressed on erythrocytes and a few other tissues in the vast majority of individuals. The minimal structure of the $\mathrm{Sd}^{\mathrm{a}}$ antigen consists of a $\alpha 2,3$-sialylated galactose to which a GalNAc residue is $\beta 1$,4-linked (Figure 1) [5]. This epitope can be carried out by various underlying sugar chains, which are indicated as R1-R5 in Figure 1. The enzyme responsible for the last step of $\mathrm{Sd}^{\mathrm{a}}$ biosynthesis is $\beta 1,4 N$-acetylgalactosaminyltransferase 2 (B4GALNT2), first identified in our laboratory [6] and successively cloned in our and other labs [7-9]. The few $\mathrm{Sd}^{\mathrm{a}}$-negative individuals display missense mutations in the C-terminal portion of the $B 4 G A L N T 2$ gene [10]. The expression of B4GALNT2 is very high in normal colonic mucosa but undergoes a dramatic downregulation in colorectal carcinoma (CRC) [11,12]. However, the level of expression in cancer samples is highly variable. In many specimens, it is undetectable, while it is relatively conserved in other cases, predicting a longer survival [13]. In mice, B4galnt2 expression influences microbiota composition [14]. The B4GALNT2 gene is comprised of 11 coding exons. There are two different alternative first exons, both containing a translational start codon. The polypeptide encoded by the transcript including Exon 1S (short form) contains a cytoplasmic tail of conventional length, whereas the one encoded by the transcript with Exon 1L (long form) possesses an exceptionally long cytoplasmic tail. 
The short form exhibits conventional Golgi localization, while the long form is localized in post-Golgi compartments as well as on the plasma membrane [15].

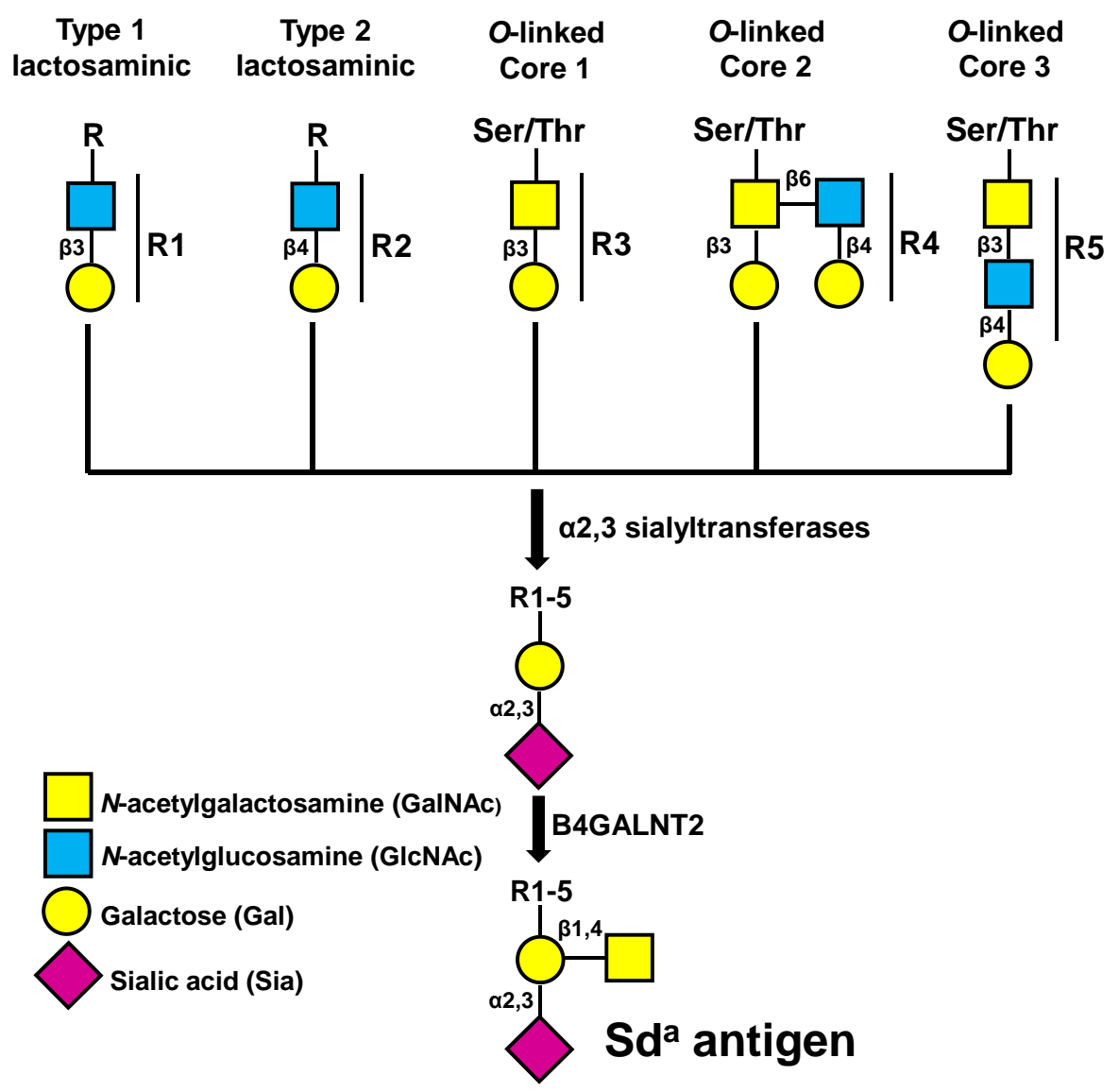

Figure 1. Schematic representation of the structure and biosynthesis of the $\mathrm{Sd}^{\mathrm{a}}$ antigen. Several carbohydrate structures (R1-R5) terminating with galactose are $\alpha 2,3$ sialylated by different $\alpha 2,3$ sialyltransferases. The resulting sialylated structure is a substrate for B4GALNT2, which generates the $\mathrm{Sd}^{\mathrm{a}}$ antigen.

The molecular bases of B4GALNT2 downregulation in colon cancer tissues and cell lines have not been fully elucidated, although methylation appears to plays a role. In fact, treatment of different colon cancer cell lines with the methylation inhibitor 5-aza2 -deoxycytidine resulted in a partial activation of B4GALNT2 expression [16,17]. The carbohydrate antigen sialyl Lewis ${ }^{\mathrm{x}}\left(\mathrm{sLe}^{\mathrm{x}}\right)$, a well-known ligand for the cell adhesion molecules of the selectin family, is ectopically expressed by many cancers and is associated with malignancy [2]. The sLe ${ }^{\mathrm{x}}$ antigen is formed by a fucose residue $\alpha 1,3$-linked to the GlcNAc residue of a $\alpha 2,3$ sialylated type 2 chain, a structure on which B4GALNT2 acts to synthesize the $\mathrm{Sd}^{\mathrm{a}}$ antigen [5]. In cell lines, the forced expression of B4GALNT2 resulted in $\mathrm{Sd}^{\mathrm{a}}$ expression and $\mathrm{sLe}^{\mathrm{x}}$ inhibition, demonstrating that biosynthesis of the two antigens is mutually exclusive $[12,18]$. These B4GALNT2-expressing cell lines displayed reduced metastatic ability $[18,19]$, which was attributed to $\mathrm{sLe}^{\mathrm{x}}$ inhibition rather than to de novo $\mathrm{Sd}^{\mathrm{a}}$ expression. However, our recent work $[13,20]$ has shown that B4GALNT2 expression decreases malignancy and stemness in different models of colon cancer cell lines, independently of sLe ${ }^{\mathrm{x}}$ inhibition. The COADREAD (colon and rectal adenocarcinoma) cohort of "The Cancer Genome Atlas" (TCGA) contains data from 626 cases. Matched tumor-normal tissue samples have been molecularly characterized to identify alterations providing insights into the biology of CRC. Molecular data are derived from multiple types of analysis including gene expression, whole genome sequences, DNA methylation, and miRNA expression. In addition, numerous metadata, including clinical information about 
participants are also available. The purpose of the present study is to gain insights into the mechanisms of regulation of B4GALNT2 expression and its association with malignancy through an in-depth analysis of data available in TCGA.

\section{Results}

2.1. The Level of Expression of Only a Few Oncogenes and Tumor Suppressor Genes Is Associated with Patient Survival

In a previous work, we reported that $B 4 G A L N T 2$ expression is a significant predictor of long-term survival in a CRC TCGA cohort [13]. To put this observation into a more general context, we asked whether tumor suppressors and oncogenes known to play fundamental roles in cancer and, in particular, in CRC were better predictors of patient survival. In Figure S1, the Kaplan-Meier survival plots of CRC patients falling in the 15\% upper or the $15 \%$ lower levels of several tumor suppressors and oncogenes are shown. The $15 \%$ threshold was chosen as a compromise between the need to focus on patients displaying extremely high or extremely low levels of gene expression and the need to include a sufficient number of patients to allow for statistical analysis. Survival curves have been ordered according to increasing $p$-value and boxed in red or blue according to the recognized tumor-promoting or tumor-suppressing activity of the genes, respectively. A statistically significant $(p \leq 0.05)$ association with survival was shown by genes SMAD6, TERT, EGFR, CDKN2A, CTNNB1, and PIK3CA, which encode the following molecules: $S M A D 6$, an inhibitor of TGF- $\beta$ signaling [21]; TERT, the reverse transcriptase subunit of telomerase; EGFR, the EGF receptor; CDKN2A, the cyclinD/CDK4,6 inhibitor $\mathrm{p} 16^{\mathrm{INK}}$ and the p53 activator $\mathrm{p} 14^{\mathrm{ARF}}$ through two partially overlapping open reading frames; CTNNB1, catenin- $\beta 1$; and PIK3CA, the catalytic $\alpha$ subunit of phosphatidylinositol-4,5-bisphosphate 3-Kinase. For the tumor promoter genes SMAD6, TERT, EGFR, and PIK3CA, low levels of expression were associated with better survival, as expected. On the contrary, the longer survival associated with low expression of the CDKN2A locus was unexpected. On the other hand, low levels of catenin- $\beta 1$ were associated with short-term poorer survival but with long-term survival. Genes for which the association with survival displayed $p$-values higher than 0.05 but lower than 0.1 included CCNE1 (cyclin E1), SMAD2, CDH1 (E-cadherin) TP53, and BRAF (B-Raf Proto-Oncogene, Serine/Threonine Kinase). Despite the established role of cyclin E1 in colon cancer promotion [22], long-term survival was associated with high CCNE1 expression. On the other hand, the associations of SMAD2, $C D H 1, T P 53$, and BRAF with survival were consistent with their biological roles. These data reveal that the expression level of only a few oncogenes and tumor suppressor genes is associated with patients' overall survival. A possible explanation for the lack of the expected relationships is provided by the fact that oncogene activation or tumor-suppressor inactivation can be due to mutations, altered phosphorylation, or mislocalization rather than increased or decreased mRNA expression.

\subsection{Among Glycosyltransferases B4GALNT2 Has a Very Good Prognostic Value in CRC}

Then, we investigated the relationship between patients' survival and the expression of several glycosyltransferases relevant for the biosynthesis of cancer-associated carbohydrate structures. In Figure 2, the Kaplan-Meier survival curves of CRC patients falling in the 15 higher percentile and the 15 lower percentile of expression of the indicated glycosyltransferase genes are reported. Each insert contains the code for the sugar transferred by that glycosyltransferase. The enzymatic reactions in which the different glycosyltransferases are involved are reported in Figure S2. Among the 26 glycosyltransferases considered, B4GALNT2 displayed the most significant association with prognosis $(p=0.03)$. In particular, long-term survivors belonged only to the high-expression group. GCNT3, the only other glycosyltransferase significantly associated with prognosis $(p=0.05)$, was previously identified as a member of a 15 glycosyltransferase prognostic signature in colon cancer [23]. However, none of the remaining 14 glycosyltransferases of that signature displayed a significant association with prognosis (data not shown). GCNT1, another 
GlcNAc transferase that shares with GCNT3 the biosynthesis of $O$-linked Core 2 structures, displayed clearly, although not significantly, the same tendency for worse prognosis shown by GCNT3. This is consistent with the recognized association of Core 2 structures with the vessel invasion and depth of tumor invasion [24]. In contrast, B3GNT6, which synthesizes the Core 3 structure displayed a clear, although nonsignificant, tendency towards an opposite prognostic value, consistent with the recognized role of Core 3 structures in preventing colitis and colon cancer [25]. Surprisingly, enzymes responsible for the biosynthesis of well-known cancer-associated structures, such as $\beta 1,6$ branching (MGAT5), sialyl-Tn

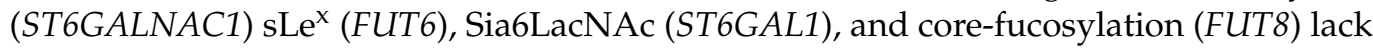
any relationship with survival. Thus, among glycosyltransferases, B4GALNT2 displays a very good prognostic value.

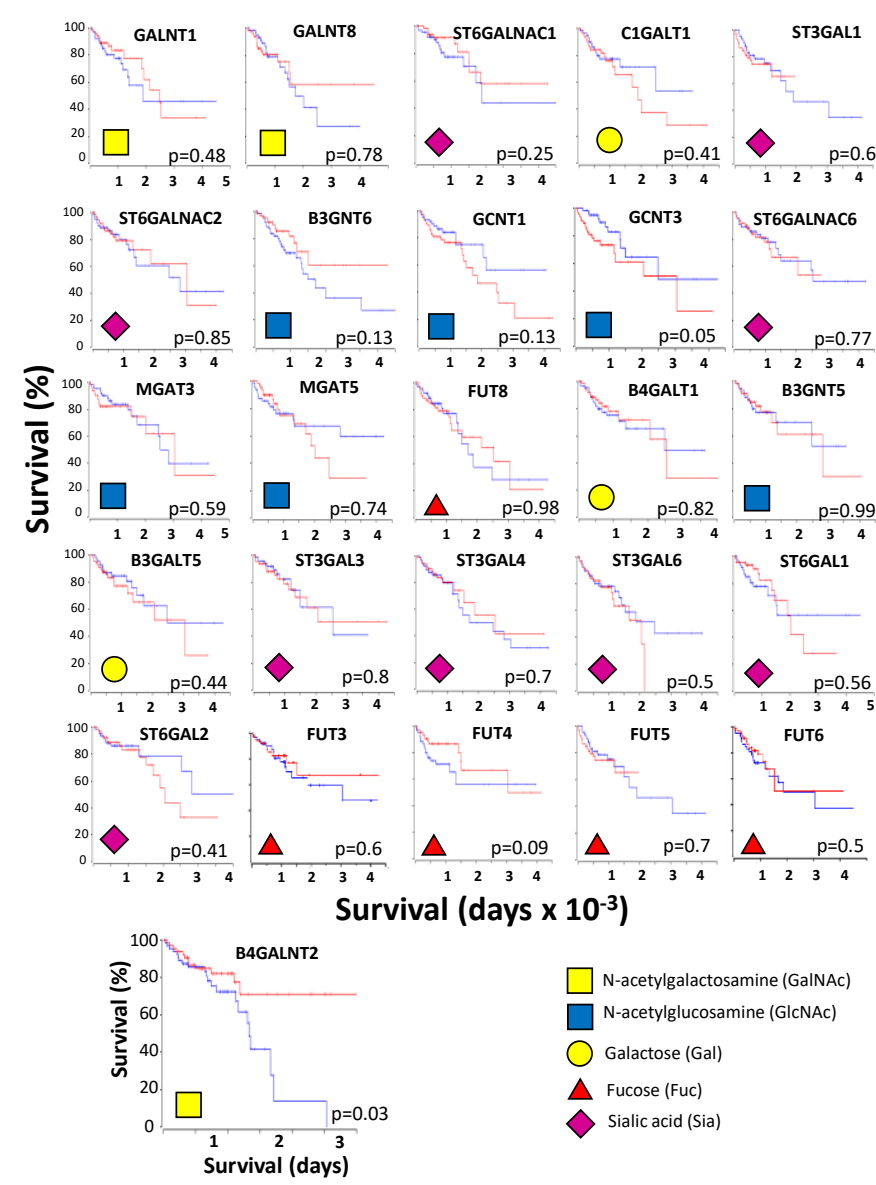

Figure 2. Kaplan-Meier survival plots of patients expressing high or low glycosyltransferase mRNA levels. Curves were generated by the OncoLnc website using the $15 \%$ higher (red lines) and 15\% lower expressions (blue lines) of the indicated genes. The sugar transferred by each glycosyltransferase is indicated by the code in the insert.

\subsection{Comparison of High and Low B4GALNT2 Expressers in the COADRED Cohort}

In the cohorts of the 15\% higher B4GALNT2 expressers (HBE) and of the $15 \%$ lower B4GALNT2 expressers (LBE) the mean \pm SD levels of B4GALNT2 expression were $0 \pm 0$ and $367 \pm 501$, respectively. In total, 614 genes displayed a significantly different level of expression in the two cohorts (Figure 3 and Table S1). The vast majority (451) of these genes displayed higher expressions in HBE, although 163 genes displayed the opposite behavior. The gene expression ratio between high/low expressers ranged from 200 to -11 . Genes showing the most remarkable changes, selected for a ratio higher than 10.0 or lower than -4.0 , have been characterized by an extensive literature search, in particular for their role in cancer (Table 1). A color code was assigned to the putative tumor-promoting or tumorrestraining role in the change as follows: green for higher expression of tumor-restraining 
genes or lower expression of tumor-promoting genes in HBE and vice versa for red. Only genes with a recognizable role in cancer were reported. A high B4GALNT2 expression was associated with 27 tumor restraining and 10 tumor promoting changes, suggesting its association with a low-malignancy molecular signature.
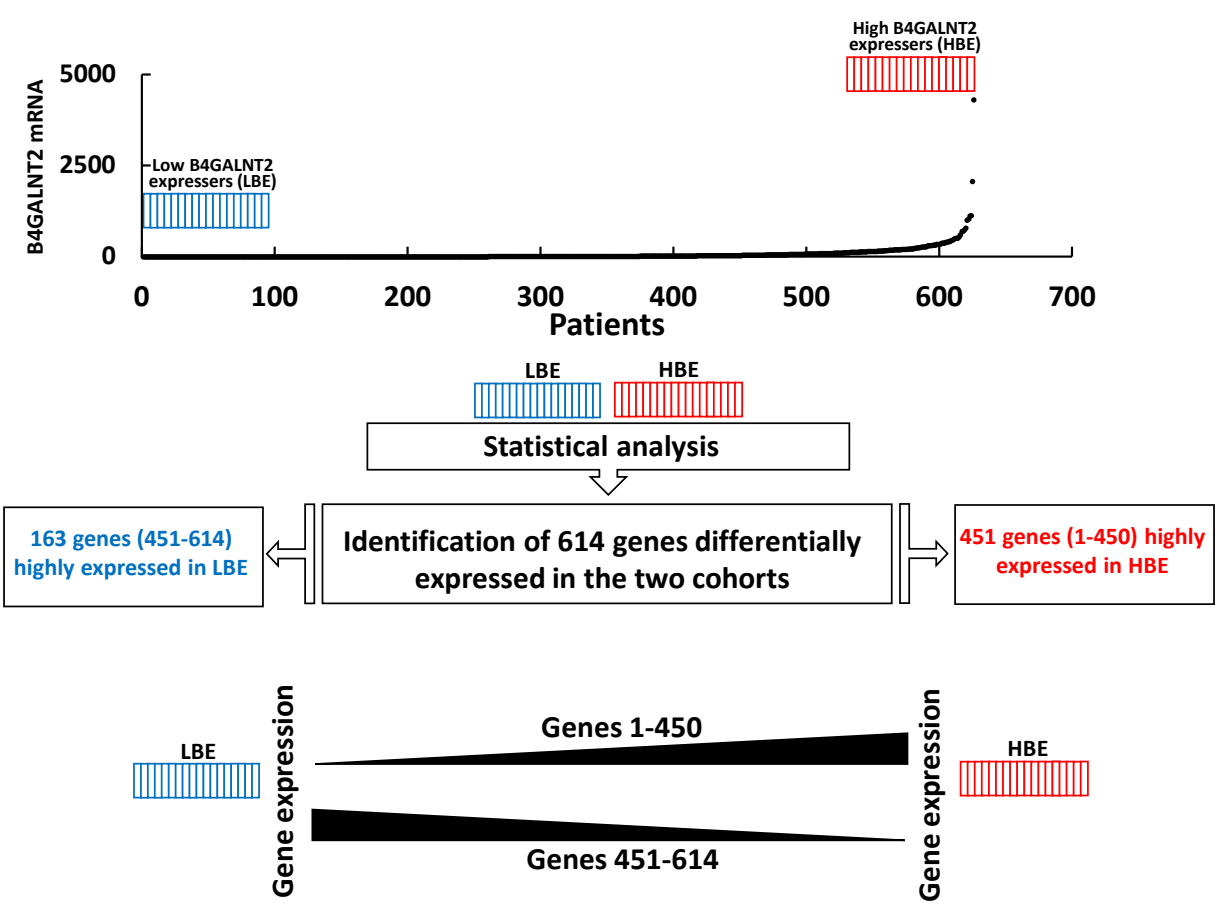

Figure 3. Schematic representation of the TCGA data analysis. The 626 COADREAD cases were ordered according to the level of B4GALNT2 expression, differentiating the $15 \%$ top expression (HBE, red) and the $15 \%$ lower expression (LBE, blue) cohorts of 94 cases. Statistical analysis (false discovery rate two-stage linear step-up procedure of Benjamini, Krieger, and Yekutieli) revealed that 614 genes were differentially expressed in the two cohorts. Of these, 451 genes were more expressed in HBE while 163 were more expressed in the LBE.

Table 1. Genes differentially modulated in HBE and LBE.

\begin{tabular}{|c|c|c|c|}
\hline Gene & Ratio & $\begin{array}{l}\text { Gene Role } \\
\end{array}$ & Reference \\
\hline CLCA1 & 203 & $\begin{array}{c}\text { Involved in mucus secretion and as a tumor suppressor and } \\
\text { suppresses CRC malignancy }\end{array}$ & 28974231 \\
\hline ZG16 & 151 & $\begin{array}{l}\text { Animal lectin; inhibits growth and increases immune } \\
\text { surveillance of CRC }\end{array}$ & [26-29] \\
\hline ITLN1 & 62 & Lectin-recognizing microbial carbohydrates; protective in CRC & {$[30-32]$} \\
\hline CLCA4 & 51 & $\begin{array}{l}\text { Involved in mediating chloride conductance; downregulated } \\
\text { genes in CRC }\end{array}$ & 32027181 \\
\hline SPINK4 & 48 & $\begin{array}{l}\text { Serine peptidase inhibitor; its downregulation is associated with } \\
\text { poor survival in CRC }\end{array}$ & 31888570 \\
\hline CA1 & 45 & Carbonic anhydrase; predictive biomarker in CRC & 32031891 \\
\hline MAGEA1 & 37 & $\begin{array}{l}\text { Involved in transcriptional regulation; acts as an oncogene in } \\
\text { some cancers }\end{array}$ & 30509089 \\
\hline$P Y Y$ & 33 & $\begin{array}{l}\text { Inhibitis intestinal mobility; decreased expression is associated } \\
\text { with CRC }\end{array}$ & 11825654 \\
\hline GUCA2B & 32 & Regulator of intestinal fluid transport; tumor suppressor in CRC & 29788743 \\
\hline CA4 & 27 & $\begin{array}{c}\text { Stimulates the ion transporter activity of SLC4A4; Predictive } \\
\text { biomarker in CRC }\end{array}$ & 32031891 \\
\hline MS4A12 & 25 & $\begin{array}{c}\text { Involved in signal transduction; promotes malignant } \\
\text { progression in CRC }\end{array}$ & 18451174 \\
\hline
\end{tabular}


Table 1. Cont.

\begin{tabular}{|c|c|c|c|}
\hline Gene & Ratio & Gene Role & Reference \\
\hline BEST2 & 23 & $\begin{array}{l}\text { Anion channel; methylation marker for early detection and } \\
\text { prognosis of CRC }\end{array}$ & [33] \\
\hline HEPACAM2 & 23 & $\begin{array}{l}\text { Required for centrosome maturation; associated with } \\
\text { good prognosis }\end{array}$ & 29659199 \\
\hline TMIGD1 & 22 & $\begin{array}{l}\text { Controls cell-cell adhesion and proliferation; tumor suppressor } \\
\text { in CRC }\end{array}$ & 33129760 \\
\hline CLDN8 & 16 & Claudin 8; component of tight junctions; downregulated in CRC & 21479352 \\
\hline B3GNT6 & 14 & $\begin{array}{c}\text { Synthesizes core } 3 \text { O-linked chains; downregulation associated } \\
\text { with malignancy in CRC }\end{array}$ & 28745318 \\
\hline KIF19 & 13 & $\begin{array}{l}\text { Microtubule-dependent motor protein; higher expression } \\
\text { associated with longer survival }\end{array}$ & 28901309 \\
\hline CSAG2 & 13 & $\begin{array}{c}\text { Chondrosarcoma-asociated gene } 2 / 3 \text { protein; necessary for } \\
\text { tumorigenesis }\end{array}$ & 32761762 \\
\hline FCGBP & 12 & $\begin{array}{l}\text { Maintains the mucosal structure; high expression is associated } \\
\text { with better prognosis }\end{array}$ & 31268166 \\
\hline CDKN2BAS & 12 & $\begin{array}{l}\text { CDKN2B antisense RNA 1; promotes progression of } \\
\text { ovarian cancer }\end{array}$ & 32572907 \\
\hline REG1B & 11 & $\begin{array}{l}\text { Regenerating islet-derived protein } 1-\beta \text {; its silencing inhibits } \\
\text { CRC growth }\end{array}$ & 25768000 \\
\hline$I G J$ & 11 & $\begin{array}{l}\text { Joining chain of multimeric IgA and IgM; downregulated } \\
\text { in CRC }\end{array}$ & 31749922 \\
\hline LEFTY2 & 10 & $\begin{array}{c}\text { Member of the TGF- } \beta \text { superfamily; negative regulator of } \\
\text { endometrial cell proliferation }\end{array}$ & 27497669 \\
\hline FUT5 & 10 & Fucosyltransferase 5; promotes the development of CRC & 28771224 \\
\hline MUC2 & 10 & $\begin{array}{l}\text { Secreted mucus-forming mucin; suppresses CRC migration and } \\
\text { metastasis }\end{array}$ & 28725043 \\
\hline PLIN1 & -4 & $\begin{array}{l}\text { Modulator of adipocyte lipid metabolism; inhibits breast cancer } \\
\text { cell proliferation }\end{array}$ & 27359054 \\
\hline PCP4 & -4 & $\begin{array}{l}\text { Functions as a modulator of calcium-binding by calmodulin; } \\
\text { antiapoptotic peptide }\end{array}$ & 25153723 \\
\hline IGF2 & -4 & $\begin{array}{l}\text { Possess growth-promoting activity; overexpression is associated } \\
\text { with poor prognosis }\end{array}$ & 24080445 \\
\hline SLC14A1 & -4 & Urea channel; cancer stem cell marker & 29329541 \\
\hline FREM1 & -5 & $\begin{array}{l}\text { Extracellular matrix protein; associated with better prognosis in } \\
\text { bladder cancer }\end{array}$ & 33058542 \\
\hline CASQ2 & -5 & $\begin{array}{l}\text { Calsequestrin; high expression associated with poor survival in } \\
\text { bladder cancer }\end{array}$ & 31991631 \\
\hline CPLX2 & -6 & $\begin{array}{l}\text { Involved in exocytosis; associated with poor prognosis in } \\
\text { lung tumors }\end{array}$ & 3912489 \\
\hline ADIPOQ & -6 & $\begin{array}{l}\text { Adiponectin; anti-inflammatory adipokine; lower expression } \\
\text { in CRC }\end{array}$ & 27061803 \\
\hline WIF1 & -7 & $\begin{array}{l}\text { Inhibits WNT actvities; hypermethylation is associated with a } \\
\text { favorable clinical outcome }\end{array}$ & 31830937 \\
\hline CHRNB2 & -9 & $\begin{array}{l}\text { Cholinergic receptor nicotinic beta } 2 \text { subunit; downregulated in } \\
\text { gastric cancer }\end{array}$ & 30175534 \\
\hline AР3B2 & -10 & $\begin{array}{l}\text { Involved in protein sorting; low expression is associated with } \\
\text { long-term survival in rectal cancer }\end{array}$ & 29050227 \\
\hline TSIX & -11 & $\begin{array}{l}\text { XIST antisense RNA; dysregulates cancer pathways in multiple } \\
\text { tumor contexts }\end{array}$ & [34] \\
\hline
\end{tabular}

Genes differentially modulated in HBE and LBE cohorts were analyzed by the false discovery rate two-stage linear step-up procedure of Benjamini, Krieger, and Yekutieli. Only genes showing upregulation $\geq 10$ or downregulation $\leq-4$ and with a recognized role in cancer, as deduced by the literature, are reported. Mean level of expression \pm SD and corrected $p$ values are reported in Table S1. "Ratio" refers to the HBE/LBE ratio. When the expression was higher in LBE, the HBE/LBE ratio was expressed preceded by a "minus" sign. The role of the gene was deduced from the website "genecards.org", whereas the role of the gene in cancer was deduced by an extensive literature search. The "Reference" column reports either the number in the Reference list or the PubMed accession number. The red or green labels indicate putative tumor-promoting or tumor-restraining changes, respectively.

To establish the prognostic potential of genes modulated with respect to B4GALNT2, the survival curves of the top 15 highly expressed genes and the 10 least expressed genes in 
HBE were obtained (Figure S3). The predictive potential of the highly regulated genes was very good, while genes poorly expressed in HBE lacked any association with prognosis. In particular, the Kaplan-Meier curves of the 15 highly regulated genes (A) were relatively similar, with strong expresser patients displaying a more or less pronounced tendency towards better prognosis (the red curve is always above the blue curve). Four genes (ZG16, ITLN1, BEST2, and GUCA2B) displayed a statistically significant relationship. The significance of ZG16, a gene previously shown to be associated with a good prognosis in CRC [26], was particularly high. The $p$-value of these genes was always lower than 0.5 , which could be indicative of a tendency, although not statistically significant. On the other hand, genes poorly expressed in HBE displayed $p$-values always above 0.5 .

\subsection{Several Glycogenes Are Differentially Modulated in HBE and LBE}

In Table 2, genes encoding glycosyltransferases as well as heavily glycosylated glycoproteins, such as mucins, and sugar binding proteins, such as galectins, for which the expressions are significantly different in HBE and LBE are reported. The vast majority of the genes listed in Table 2 displayed higher expressions in HBE. In particular, we observed a 10-fold higher expression of GALNT8, mediating the first step of O-glycan biosynthesis (Figure S2), and a 14-fold higher expression of B3GNT6, the enzyme mediating the biosynthesis of Core 3 structures. Since the decrease in Core 3 structures is associated with colon cancer [35], the higher expression of B3GNT6 is consistent with a colon cancer phenotype closer to normal. In addition, Core 3 structures are major $\mathrm{Sd}^{\mathrm{a}}$ carriers in normal colon [36]. On the other hand, HBE displayed higher levels of expression of the sialyltransferases ST6GALNAC1 and ST6GALNAC2, which are responsible for biosynthesis of the tumor-associated antigens sialyl-Tn and sialyl-6-T. Galactosyltransferase B3GALT5 is a key enzyme in the biosynthesis of type 1 lactosaminic chains (Galß1,3GlcNAc) highly expressed in normal colon but downregulated in CRC [37]. Its higher expression in HBE is consistent with an association with lower malignancy. $\alpha 2,3$-sialylation of type 2 chains, which is mediated (among other STs) by ST3GAL4, is a necessary step in $\mathrm{Sd}^{\mathrm{a}}$ biosynthesis. Concomitantly high ST3GAL4 and B4GALNT2 expressions in the same tissue are expected to support a strong level of $\mathrm{Sd}^{\mathrm{a}}$ biosynthesis. On the other hand, the 10-fold higher expression of FUT5, which mediates sLe $\mathrm{x}^{\mathrm{x}}$ biosynthesis and acts as a possible competitor of B4GALNT2, reduces Sd ${ }^{a}$ expression. ST6GAL1 and ST6GAL2, which catalyze the $\alpha 2,6$ siaylation of glycoproteins [38] and oligosaccharides [39], are the only two glycogenes that display lower expressions in HBE. ST6GAL1 is overexpressed in CRC [40] and is associated with increased malignancy at the protein level [41] but not at the mRNA level [42].

Table 2. Expression level of glycogenes in HBE and LBE.

\begin{tabular}{|c|c|c|c|}
\hline Functional Class & Gene & Ratio & Role \\
\hline \multirow{4}{*}{$\begin{array}{l}\text { First steps of } O \text {-linked } \\
\text { biosynthesis }\end{array}$} & GALNT8 & 9.5 & $\begin{array}{l}\text { Addition of the first GalNAc } \\
\text { residue of the } O \text {-linked chains }\end{array}$ \\
\hline & B3GNT6 & 14.4 & $\begin{array}{l}\text { Synthesis of Core } 3 \text { O-glycans by } \\
\text { attaching GlcNAc to GalNAc }\end{array}$ \\
\hline & ST6GALNAC1 & 5.4 & $\begin{array}{l}\text { Synthesis of sialyl Tn by } \\
\text { attaching Sia to GalNAc }\end{array}$ \\
\hline & ST6GALNAC2 & 2.1 & $\begin{array}{l}\text { Synthesis of sialyl } \mathrm{T} \text { by attaching } \\
\text { Sia to GalNAc of } \mathrm{T} \text { antigen }\end{array}$ \\
\hline $\begin{array}{l}\text { Ganglioside } \\
\text { biosynthesis }\end{array}$ & ST6GALNAC6 & 2.5 & Synthesis of higher gangliosides \\
\hline $\begin{array}{l}\text { Proteoglycan } \\
\text { biosynthesis }\end{array}$ & B3GNT7 & 6.3 & Keratan sulfate biosynthesis \\
\hline
\end{tabular}


Table 2. Cont.

\begin{tabular}{|c|c|c|c|}
\hline Functional Class & Gene & Ratio & Role \\
\hline \multirow{3}{*}{$\begin{array}{l}\text { Biosynthesis of sialyl } \\
\text { Lewis antigens }\end{array}$} & B3GALT5 & 4.0 & Synthesis of type 1 chains \\
\hline & ST3GAL4 & 4.0 & Sialylation of type 2 chains \\
\hline & FUT5 & 10.8 & Fucosylation of type 2 chains \\
\hline \multirow{2}{*}{$\begin{array}{l}\text { Biosynthesis of Sia6 } \\
\text { LacNAc structures }\end{array}$} & ST6GAL1 & -2.0 & $\alpha 2,6$ sialylation of glycoproteins \\
\hline & ST6GAL2 & -2.7 & $\begin{array}{l}\alpha 2,6 \text { sialylation of soluble } \\
\text { substrates }\end{array}$ \\
\hline \multirow{2}{*}{ Galactose recognition } & LGALS4 & 2.0 & $\begin{array}{c}\text { Galectin 4, expressed in the gut, } \\
\text { underexpressed in CRC }\end{array}$ \\
\hline & $L G A L S 9 B$ & 2.2 & Highly similar to Galectin 9 \\
\hline \multirow{4}{*}{ O-glycoproteins } & MUC1 & 2.0 & $\begin{array}{l}\text { Membrane bound mucin with } \\
\text { multiple functions }\end{array}$ \\
\hline & MUC2 & 10.4 & Secreted mucus forming mucin \\
\hline & MUC4 & 5.2 & Membrane and secreted mucin \\
\hline & MUC5B & 2.6 & Gel-forming mucin \\
\hline
\end{tabular}

The role of glycosyltransferases is indicated in Supplementary Figure S2. Mean level of expression \pm SD and corrected $p$-values are reported in Table S1. "Ratio" indicates the ratio between gene expression in HBE/LBE. When the expression was higher in LBE, the HBE/LBE ratio was expressed with a "minus" sign.

\subsection{The Role of Methylation in B4GALNT2 Expression}

The presence of $\mathrm{CpG}$ islands in the promoter region of the B4GALNT2 gene suggests that methylation can play a relevant role in B4GALNT2 downregulation in colon carcinogenesis. The methylation probes used by the TCGA characterization covered the $\mathrm{CpG}$ island as well as a Northern shore (N-shore, upstream the island), a Southern shore (S-shore, downstream the island), and an intronic (open-sea) position between exons 6 and 7 (Figure 4A). At first sight, several differences were evident between normal and tumor methylation (Figure 4B). Which insights do these data provide into the role of methylation in the general downregulation of B4GALNT2 mRNA observed in colon cancer? Methylation in both the N-shore and the S-shore was never statistically different between normal and tumor tissues, although in the latter the extent of methylation was more heterogeneous among patients (Figure 4B). Consequently, these changes cannot be responsible for the general B4GALNT2 downregulation in cancer. Seven positions within the island (cg01147550-cg18208707 and cg02445664) displayed very low levels of methylation in both normal and the vast majority of tumor tissues, ruling out their major role in cancer-associated B4GALNT2 downregulation. Positions cg20233029 and cg03167683 in the island displayed a small but significantly reduced methylation in tumor tissues. However, to explain the reduced B4GALNT2 expression, methylation of these sites should be increased rather than decreased. Methylation of the "open sea" intronic site cg043380107 displayed a highly significant and very heterogeneous reduction in cancer. As shown in Figure 4C, which reports the correlation between B4GALNT2 expression and methylation status of the 16 sites in tumor tissues, in some cases, methylation results in enhancement, rather than inhibition, of gene expression. This is particularly true for the intronic site $\operatorname{cg} 043380107$, in which the highest B4GALNT2 expression levels are associated with high methylation. Except for the first two sites in the N-shore, in all of the remaining sites, low methylation is a prerequisite for high B4GALNT2 expression, although many samples displaying very low methylation failed to express B4GALNT2 (Figure 4C). Altogether, these data point to reduced methylation of the intronic site as a key factor in accounting for the general reduction of B4GALNT2 expression in CRC and demonstrated that, among CRC samples, low methylation of the island and shore sites is a necessary but not sufficient condition for high B4GALNT2 expression. 


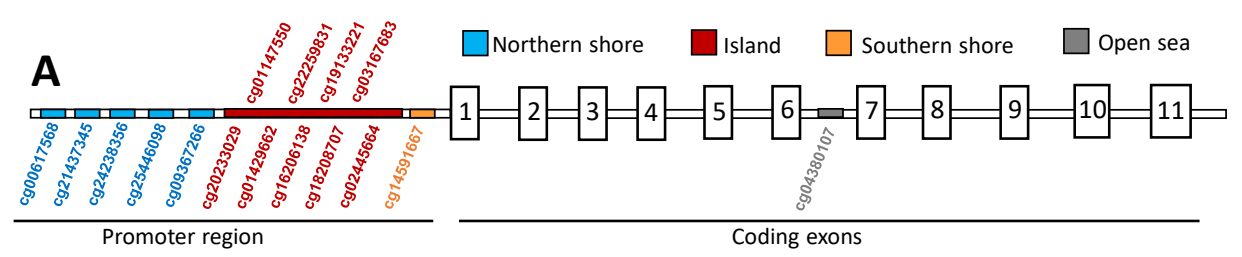

B

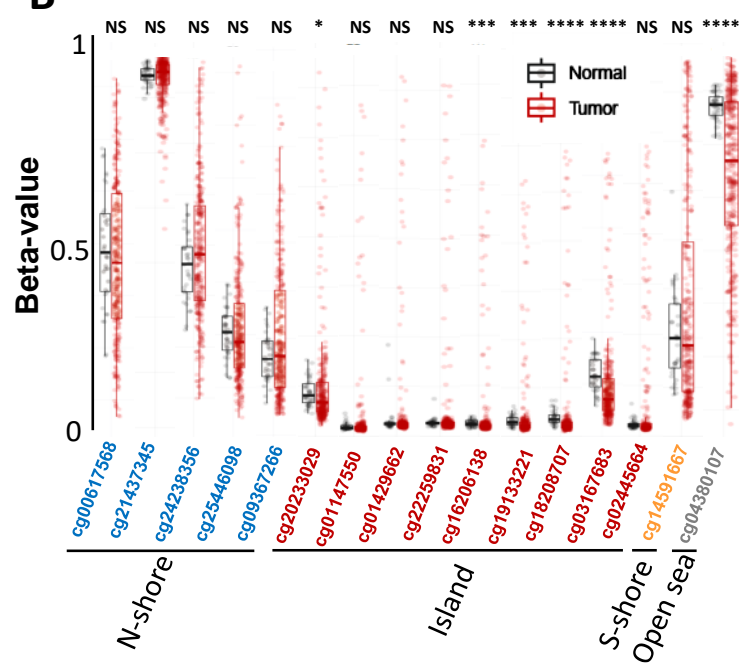

\section{C}

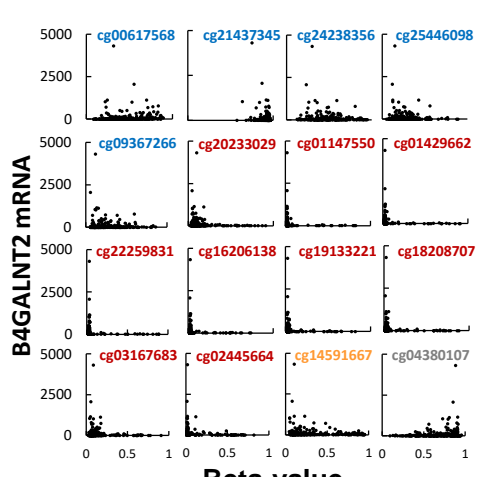

Beta-value

Figure 4. DNA methylation of the B4GALNT2 gene. (A) Schematic representation, not drawn to scale, of the promoter region and of the coding exons of the B4GALNT2 gene. The approximate position of the probes is indicated. (B) Methylation level of the different probes. ${ }^{*} p<0.05 ;{ }^{* * *} p<0.001{ }^{* * * *} p<0.0001$. (C) Correlation between B4GALNT2 expression level and methylation of specific positions in tumor tissues.

\subsection{The Role of miRNAs in B4GALNT2 Expression}

The potential role of miRNAs in the regulation of B4GALNT2 expression was investigated. Preliminarily, a list of miRNA potentially targeting B4GALNT2 in colorectal cancer was obtained from the CSmiRTar database. Only miRNA supported by at least two of the four miRNA target prediction databases and with a "normalized miRNA score, NMR" $>0.2$ (Figure 5A) were considered. The mean level of miRNA expression was determined in the LBE and HBE groups. In consideration of the different number of TCGA patients for which miRNA data were available, we included in the LBE and HBE cohorts the top lower and top higher expressers displaying a mean level of B4GALNT2 expression closest to that of the LBE and HBE cohorts shown in Figure 3 ( 0 and 367, respectively). Five miRNA displayed little and nonsignificant differences between LBE and HBE (Figure 5A). On the other hand, miR-204-5p was nearly 3-fold less expressed in HBE than in LBE $(p=0.002)$. A correlation dot plot (Figure 5B) revealed that miR-204-5p was never expressed in HBE patients, although several patients not expressing miR-204-5p failed to express B4GALNT2. These data strongly suggest that downregulation of miR-204-5p is a necessary but not sufficient condition for B4GALNT2 expression in CRC tissues. 


\section{A}

Expression of miRNA potentially targeting B4GALNT2 in LBE and HBE cohorts

\begin{tabular}{llllcl}
\hline \multicolumn{1}{c}{ miRNA } & Mean NMS* & LBE & HBE & LBE/HBE Ratio & $p^{*}$ \\
\hline hsa-miR-105-5p & 0.664 & 15 & 22.5 & 0.67 & 0.28 \\
hsa-miR-145-5p & 0.652 & 2065 & 1854 & 1.1 & 0.28 \\
hsa-miR-204-5p & $\mathbf{0 . 5 9 4}$ & $\mathbf{9 . 5}$ & $\mathbf{3 . 2}$ & $\mathbf{2 . 9 7}$ & $\mathbf{0 . 0 0 2}$ \\
hsa-miR-150-3p & 0.449 & 2.1 & 2.6 & 0.81 & 0.12 \\
hsa-miR-146b-3p & 0.289 & 64.4 & 72.6 & 0.89 & 0.23 \\
hsa-miR-134-5p & 0.272 & 293 & 285 & 1.0 & 0.38 \\
\hline
\end{tabular}

\section{B}

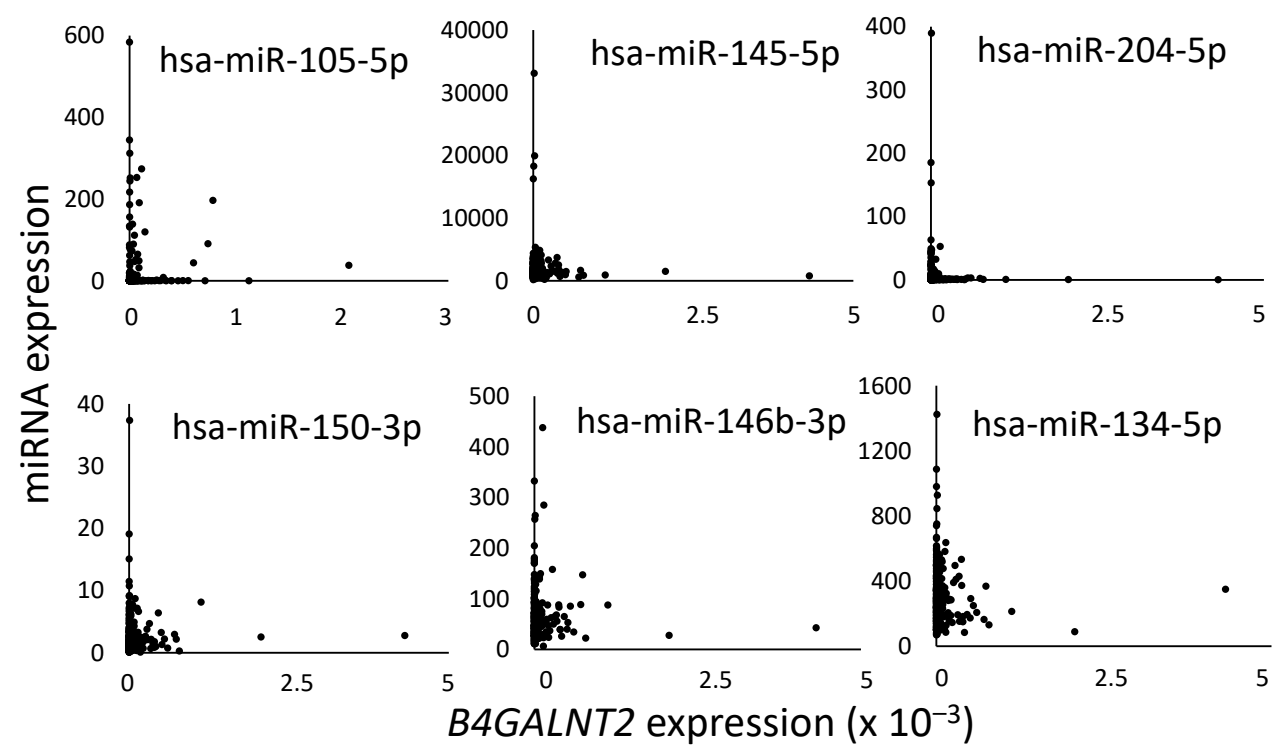

Figure 5. Correlation of B4GALNT2 and miRNA expression. (A) miRNA potentially targeting B4GALNT2 were obtained from the CSmiRTar database. Only miRNA supported by at least two of the four miRNA prediction target databases and with a "normalized miRNA score, NMR" $>0.2$ were considered. LBE and HBE represent the expression of the miRNA in the LBE (B4GALNT2 expression = 0) or HBE (B4GALNT2 expression closest to 367) cohorts. The only significantly modulated miRNA is indicated in bold. * Student's t test for independent samples. (B) dot plot correlation analysis of the miRNA and B4GALNT2 expression level.

\section{Discussion}

In this study, we showed that B4GALNT2 mRNA expression exhibits a prognostic predictive potential in CRC much better than that of all of the glycosyltransferases tested and even better that that of many oncogenes and tumor-suppressor genes. Among those tested, only SMAD6 and TERT displayed better prognostic values than B4GALNT2, which equals that of EGFR (Figure S1). Patient stratification according to B4GALNT2 expression revealed that $\mathrm{HBE}$ group displayed a concomitantly high level of other genes associated with positive prognosis, such as ZG16, ITLN1, BEST2, and GUCA2B. (Table 1). ZG16 is an animal homologue of a plant lectin [43] that inhibits the growth of colon cancer cell lines and CRC-derived organoids by binding with cell surface sugars [29]. In addition, it downregulates PD-L1 expression in CRC, promoting immune surveillance [27]. ITLN1 is associated with good prognosis in CRC [30,32]. It encodes a lectin known as intelectin-1 or omentin-1, which acts as a tumor suppressor in CRC [31]. Apart from its association with good prognosis in CRC [33], no more information is available for BEST2. The product of the GUCA2B gene, in cooperation with those of GUCA2A and GUCA2C, regulates 
proliferation, metabolism, and barrier function in the intestine [44]. In long- and short duration ulcerative colitis, GUCA2B displays a differential expression in parallel with B4GALNT2 [45]. Among the genes more dramatically downregulated in HBE, TSIX is of particular interest. It is a long noncoding RNA (lncRNA) known to be the anti-sense inhibitor of XIST, which is responsible for the epigenetic inactivation of one of the two $\mathrm{X}$ chromosomes in female cells. However, TSIX has also been shown to synergistically regulate, together with other lncRNAs, cancer genes and pathways across multiple tumor contexts [34]. Altogether, these data support the notion that B4GALNT2 is a key member of a gene signature associated with good prognosis. Amongst the genes differentially expressed in HBE and LBE, several are involved in glycosylation (Table 2). Differential expression of several glycosyltransferases predicts that cancer cells of HBE display higher levels of mucin-type O-glycosylation (GALNT8) with sugar chains terminating with sialylTn, (ST6GALNAC1), sialyl-6-T structures (ST6GALNAC2), and Core 3 structures (B3GNT6); increased biosynthesis of type 1 chains (B3GALT5); and increased $\alpha 2,3$ sialylation of type 2 chains (ST3GAL4), forming acceptor substrates for B4GALNT2. Despite the higher expression of FUT5, more biosynthesis of sLe ${ }^{\mathrm{x}}$ does not appear to be likely, considering the competition of B4GALNT2. Owing to the reduced expressions of both ST6GAL1 and ST6GAL2, $\alpha 2,6$-sialylation could be reduced in HBE. Among non-glycosyltransferase molecules, it is worth mentioning the higher expression of galectin 4 , which is associated with normal gut, and of the gel-forming mucins MUC2, MUC4, and MUC5B. These data support the existence of different glycophenotypes in the LBE and HBE cohorts.

Current data indicate that B4GALNT2 control in colonic tissues consists of complex mechanisms. We showed that DNA-methylation plays an important, although unconventional, role (Figure 4). In fact, its general downregulation observed in the vast majority of cancer cases cannot be explained by differential methylation of CpG sites located on the island and shores. Rather, the open-sea site located at the intron between exons 6 and 7 presents generally reduced methylation in cancer samples. Interestingly, methylation of this site is associated with increased, rather than decreased, B4GALNT2 expression. In some cases, the stimulatory effect of high methylation of specific sequences is due to the fact that it promotes interactions between distant enhancers and the regulatory regions of the gene [46]. However, regardless a permissive methylation status, in many samples, B4GALNT2 was not expressed, indicating that other regulatory mechanisms are involved. This is in agreement with a previous study showing that differential B4GALNT2 promoter methylation is only partially correlated with gene expression in gastric cancer cell lines [17]. miRNAs are potential candidates for B4GALNT2 regulation. Among the miRNAs theoretically predicted to inhibit $B 4 G A L N T 2$, miR-204-5p appears to be the most plausible candidate (Figure 5). In fact, it is the only one downregulated in HBE and none of the samples expressing B4GALNT2 above a background threshold expressed this miRNA. However, miR-204-5p downregulation does not ensure B4GALNT2 expression, since many cases lacking miR-204-5p failed to express B4GALNT2. Together, these data indicate a multifactorial nature of B4GALNT2 regulation, with DNA methylation and miRNA expression playing relevant but not exclusive roles. It appears that, even without methylation and miRNA "brakes", the "engine" of B4GALNT2 transcription does not run. The lack of appropriate transcription factors is a plausible reason for the lack of B4GALNT2 expression in the majority of CRC samples. Our previous data indicate that forced B4GALNT2 expression is responsible for attenuation of the neoplastic phenotype and of stemness in different CRC cell models [13,20]. On this basis, the stimulation of B4GALNT2 expression in CRC cells can be proposed as a promising goal for therapy of this deadly disease.

\section{Materials and Methods}

Kaplan-Meier survival curves were obtained from the Oncolnc website (oncolnc.org), selecting the COAD cohort and the 15 higher and the 15 lower percentiles of gene expression. Gene expression data of 626 colorectal adenocarcinoma (COADREAD) samples were downloaded from the TCGA database using the Firebrowse website (http:/ / firebrowse.org 
(accessed on 11 April 2021)). The gene methylation data of 288 tumor samples were downloaded from TCGA. A comparison with gene methylation between normal and cancer tissues was performed using the Smartapp tool (http:/ / www.bioinfo-zs.com/smartapp/ (accessed on 11 April 2021)). A search for miRNAs targeting B4GALNT2 was completed using the CSmiRTar website (http: / / cosbi4.ee.ncku.edu.tw/CSmiRTar/ (accessed on 11 April 2021)), selecting "cancer" as "class of disease"; "colorectal cancer" as "disease", and "colorectum" as "tissue". Only miRNA predicted by at least two databases were considered. The number of TCGA patients for which miRNA expression data were available varied for different miRNA from 221 and 298.

Patients were ordered according to increasing levels of B4GALNT2 expression. Two cohorts (LBE and HBE) containing 94 patients falling in the 15\% low percentile and 15\% high percentile, respectively, were selected. Genes differentially modulated in the HBE and LBE cohorts were analyzed by the false discovery rate two-stage linear step-up procedure of Benjamini, Krieger, and Yekutieli. The role of the genes was deduced from the website "genecards.org", while the role of the genes in cancer was deduced by an extensive PubMed search using the "gene name" and "cancer" as search terms.

Supplementary Materials: The following are available online at https:/ /www.mdpi.com/article/10 $.3390 /$ ijms22094331/s1.

Author Contributions: Conceptualization, F.D.; formal analysis, M.P.; investigation, M.P. and N.M.; writing—original draft preparation, F.D.; writing—review and editing, N.M., M.P., and F.D.; supervision, F.D.; funding acquisition, F.D. All authors have read and agreed to the published version of the manuscript.

Funding: This research was funded by the University of Bologna and by the "Pallotti" Legacy for Cancer Research to F.D.

Institutional Review Board Statement: Not applicable.

Informed Consent Statement: Not applicable.

Data Availability Statement: Not applicable.

Conflicts of Interest: The authors declare no conflict of interest.

$\begin{array}{ll}\text { Abbreviations } \\ \text { COADREAD } & \begin{array}{l}\text { colon adenocarcinoma rectal adenocarcinoma } \\ \text { colorectal cancer } \\ \text { higher B4GALNT2 expressers }\end{array} \\ \text { HBE } & \text { lower B4GALNT2 expressers } \\ \text { LBE } & \text { long noncoding RNA } \\ \text { lncRNA } & \text { normalized miRNA score } \\ \text { NMR } & \text { programmed death ligand-1 } \\ \text { PD-L1 } & \text { Sialyl Lewis } \\ \text { SLe } & \text { The Cancer Genome Atlas } \\ \text { TCGA } & \end{array}$

\section{References}

1. Varki, A. Biological roles of glycans. Glycobiology 2017, 27, 3-49. [CrossRef]

2. Dall'Olio, F.; Malagolini, N.; Trinchera, M.; Chiricolo, M. Mechanisms of cancer-associated glycosylation changes. Front. Biosci. 2012, 17, 670-699. [CrossRef]

3. Dall'Olio, F.; Malagolini, N.; Trinchera, M.; Chiricolo, M. Sialosignaling: Sialyltransferases as engines of self-fueling loops in cancer progression. Biochim. Biophys. Acta 2014, 1840, 2752-2764. [CrossRef] [PubMed]

4. Pinho, S.S.; Reis, C.A. Glycosylation in cancer: Mechanisms and clinical implications. Nat. Rev. Cancer 2015, 15, 540-555. [CrossRef] [PubMed]

5. Dall'Olio, F.; Malagolini, N.; Chiricolo, M.; Trinchera, M.; Harduin-Lepers, A. The expanding roles of the Sd ${ }^{a} /$ Cad carbohydrate antigen and its cognate glycosyltransferase B4GALNT. Biochim. Biophys. Acta 2014, 1840, 443-453. [CrossRef]

6. Serafini-Cessi, F.; Dall'Olio, F. Guinea-pig kidney $\beta-\mathrm{N}$-acetylgalactosaminyltransferase towards Tamm-Horsfall glycoprotein. Requirement of sialic acid in the acceptor for transferase activity. Biochem. J. 1983, 215, 483-489. [CrossRef] 
7. Lo Presti, L.; Cabuy, E.; Chiricolo, M.; Dall'Olio, F. Molecular Cloning of the Human $\beta 1,4$ N-Acetylgalactosaminyltransferase Responsible for the Biosynthesis of the Sd ${ }^{a}$ Histo-Blood Group Antigen: The Sequence Predicts a Very Long Cytoplasmic Domain. J. Biochem. 2003, 134, 675-682. [CrossRef] [PubMed]

8. Montiel, M.D.; Krzewinski-Recchi, M.A.; Delannoy, P.; Harduin-Lepers, A. Molecular cloning, gene organization and expression of the human UDP-GalNAc:Neu5Ac $\alpha 2-3 \mathrm{Gal} \beta-\mathrm{R} \beta 1,4-\mathrm{N}$-acetylgalactosaminyltransferase responsible for the biosynthesis of the blood group Sda/Cad antigen: Evidence for an unusual extended cytoplasmic domain. Biochem. J. 2003, 373, 369-379. [CrossRef]

9. Smith, P.L.; Lowe, J.B. Molecular cloning of a murine N-acetylgalactosamine transferase cDNA that determines expression of the T lymphocyte-specific CT oligosaccharide differentiation antigen. J. Biol. Chem. 1994, 269, 15162-15171. [CrossRef]

10. Stenfelt, L.; Hellberg, A.; Moller, M.; Thornton, N.; Larson, G.; Olsson, M.L. Missense mutations in the C-terminal portion of the B4GALNT2-encoded glycosyltransferase underlying the Sd(a-) phenotype. Biochem. Biophys. Rep. 2019, 19, 100659. [CrossRef]

11. Malagolini, N.; Dall'Olio, F.; Di Stefano, G.; Minni, F.; Marrano, D.; Serafini-Cessi, F. Expression of UDP-GalNAc:NeuAc $\alpha 2,3$ Gal $\beta$-R beta 1,4(GalNAc to Gal) N-acetylgalactosaminyltransferase involved in the synthesis of $\mathrm{Sd}^{\mathrm{a}}$ antigen in human large intestine and colorectal carcinomas. Cancer Res. 1989, 49, 6466-6470.

12. Malagolini, N.; Santini, D.; Chiricolo, M.; Dall'Olio, F. Biosynthesis and expression of the Sd ${ }^{a}$ and sialyl Lewis $x$ antigens in normal and cancer colon. Glycobiology 2007, 17, 688-697. [CrossRef]

13. Pucci, M.; Gomes Ferreira, I.; Orlandani, M.; Malagolini, N.; Ferracin, M.; Dall'Olio, F. High Expression of the Sd ${ }^{a}$ Synthase B4GALNT2 Associates with Good Prognosis and Attenuates Stemness in Colon Cancer. Cells 2020, 9, 948. [CrossRef]

14. Staubach, F.; Kunzel, S.; Baines, A.C.; Yee, A.; McGee, B.M.; Backhed, F.; Baines, J.F.; Johnsen, J.M. Expression of the bloodgroup-related glycosyltransferase B4galnt2 influences the intestinal microbiota in mice. ISME J. 2012, 6, 1345-1355. [CrossRef] [PubMed]

15. Groux-Degroote, S.; Schulz, C.; Cogez, V.; Noel, M.; Portier, L.; Vicogne, D.; Solorzano, C.; Dall'Olio, F.; Steenackers, A.; Mortuaire, M.; et al. The extended cytoplasmic tail of the human B4GALNT2 is critical for its Golgi targeting and post-Golgi sorting. FEBS J. 2018, 285, 3442-3463. [CrossRef]

16. Wang, H.R.; Hsieh, C.Y.; Twu, Y.C.; Yu, L.C. Expression of the human Sd $\mathrm{a}^{\mathrm{a}} \beta-1,4-\mathrm{N}$-acetylgalactosaminyltransferase II gene is dependent on the promoter methylation status. Glycobiology 2008, 18, 104-113. [CrossRef] [PubMed]

17. Kawamura, Y.I.; Toyota, M.; Kawashima, R.; Hagiwara, T.; Suzuki, H.; Imai, K.; Shinomura, Y.; Tokino, T.; Kannagi, R.; Dohi, T. DNA hypermethylation contributes to incomplete synthesis of carbohydrate determinants in gastrointestinal cancer. Gastroenterology 2008, 135, 142-151. [CrossRef] [PubMed]

18. Kawamura, Y.I.; Kawashima, R.; Fukunaga, R.; Hirai, K.; Toyama-Sorimachi, N.; Tokuhara, M.; Shimizu, T.; Dohi, T. Introduction of $\mathrm{Sd}^{\mathrm{a}}$ carbohydrate antigen in gastrointestinal cancer cells eliminates selectin ligands and inhibits metastasis. Cancer Res. 2005, 65, 6220-6227. [CrossRef]

19. Kawamura, Y.I.; Adachi, Y.; Curiel, D.T.; Kawashima, R.; Kannagi, R.; Nishimoto, N.; Dohi, T. Therapeutic adenoviral gene transfer of a glycosyltransferase for prevention of peritoneal dissemination and metastasis of gastric cancer. Cancer Gene Ther. 2014, 21, 427-433. [CrossRef] [PubMed]

20. Pucci, M.; Gomes, F.I.; Malagolini, N.; Ferracin, M.; Dall'Olio, F. The Sd ${ }^{\text {a }}$ Synthase B4GALNT2 Reduces Malignancy and Stemness in Colon Cancer Cell Lines Independently of Sialyl Lewis X Inhibition. Int. J. Mol. Sci. 2020, 21, 6558. [CrossRef]

21. Jung, B.; Staudacher, J.J.; Beauchamp, D. Transforming Growth Factor beta Superfamily Signaling in Development of Colorectal Cancer. Gastroenterology 2017, 152. [CrossRef]

22. Cheasley, D.; Pereira, L.; Sampurno, S.; Sieber, O.; Jorissen, R.; Xu, H.; Germann, M.; Yuqian, Y.; Ramsay, R.G.; Malaterre, J. Defective Myb Function Ablates Cyclin E1 Expression and Perturbs Intestinal Carcinogenesis. Mol. Cancer Res. 2015, 13, 1185-1196. [CrossRef]

23. Noda, M.; Okayama, H.; Tachibana, K.; Sakamoto, W.; Saito, K.; Thar Min, A.K.; Ashizawa, M.; Nakajima, T.; Aoto, K.; Momma, T.; et al. Glycosyltransferase gene expression identifies a poor prognostic colorectal cancer subtype associated with mismatch repair deficiency and incomplete glycan synthesis. Clin. Cancer Res. 2018, 24, 4468-4481. [CrossRef]

24. Shimodaira, K.; Nakayama, J.; Nakamura, N.; Hasebe, O.; Katsuyama, T.; Fukuda, M. Carcinoma-associated expression of core 2 $\beta 1,6-\mathrm{N}$-acetylglucosaminyltransferase gene in human colorectal cancer: Role of O-glycans in tumor progression. Cancer Res. 1997, 57, 5201-5206. [PubMed]

25. An, G.; Wei, B.; Xia, B.; McDaniel, J.M.; Ju, T.; Cummings, R.D.; Braun, J.; Xia, L. Increased susceptibility to colitis and colorectal tumors in mice lacking core 3-derived O-glycans. J. Exp. Med. 2007, 204, 1417-1429. [CrossRef] [PubMed]

26. Meng, H.; Li, W.; Boardman, L.A.; Wang, L. Loss of ZG16 is associated with molecular and clinicopathological phenotypes of colorectal cancer. BMC. Cancer 2018, 18, 433. [CrossRef] [PubMed]

27. Meng, H.; Ding, Y.; Liu, E.; Li, W.; Wang, L. ZG16 regulates PD-L1 expression and promotes local immunity in colon cancer. Transl. Oncol. 2021, 14. [CrossRef] [PubMed]

28. Meng, Q.; Ren, C.; Wang, L.; Zhao, Y.; Wang, S. Knockdown of ST6Gal-I inhibits the growth and invasion of osteosarcoma MG-63 cells. Biomed. Pharmacother. 2015, 72. [CrossRef] [PubMed]

29. Mito, A.; Nakano, Y.; Saitoh, T.; Gouraud, S.S.S.; Yamaguchi, Y.; Sato, T.; Sasaki, N.; Kojima-Aikawa, K. Lectin ZG16p inhibits proliferation of human colorectal cancer cells via its carbohydrate-binding sites. Glycobiology 2018, 28, 21-31. [CrossRef]

30. Liu, J.; Jiang, C.; Xu, C.; Wang, D.; Shen, Y.; Liu, Y.; Gu, L. Identification and development of a novel invasion-related gene signature for prognosis prediction in colon adenocarcinoma. Cancer Cell Int. 2021, 21, 101. [CrossRef] 
31. Kawashima, K.; Maeda, K.; Saigo, C.; Kito, Y.; Yoshida, K.; Takeuchi, T. Adiponectin and Intelectin-1: Important Adipokine Players in Obesity-Related Colorectal Carcinogenesis. Int. J. Mol. Sci. 2017, 18, 866. [CrossRef]

32. Liu, X.; Bing, Z.; Wu, J.; Zhang, J.; Zhou, W.; Ni, M.; Meng, Z.; Liu, S.; Tian, J.; Zhang, X.; et al. Integrative Gene Expression Profiling Analysis to Investigate Potential Prognostic Biomarkers for Colorectal Cancer. Med. Sci. Monit. 2020, 26, e918906. [CrossRef] [PubMed]

33. Qin, L.; Zeng, J.; Shi, N.; Chen, L.; Wang, L. Application of weighted gene coexpression network analysis to explore the potential diagnostic biomarkers for colorectal cancer. Mol. Med. Rep. 2020, 21, 2533-2543. [CrossRef] [PubMed]

34. Chiu, H.S.; Somvanshi, S.; Patel, E.; Chen, T.W.; Singh, V.P.; Zorman, B.; Patil, S.L.; Pan, Y.; Chatterjee, S.S.; Sood, A.K.; et al. Pan-Cancer Analysis of lncRNA Regulation Supports Their Targeting of Cancer Genes in Each Tumor Context. Cell Rep. 2018, 23. [CrossRef] [PubMed]

35. Holst, S.; Wuhrer, M.; Rombouts, Y. Glycosylation characteristics of colorectal cancer. Adv. Cancer Res. 2015, 126, $203-256$.

36. Capon, C.; Maes, E.; Michalski, J.C.; Leffler, H.; Kim, Y.S. Sd ${ }^{\mathrm{a}}$-antigen-like structures carried on core 3 are prominent features of glycans from the mucin of normal human descending colon. Biochem. J 2001, 358, 657-664. [CrossRef]

37. Salvini, R.; Bardoni, A.; Valli, M.; Trinchera, M. $\beta 1,3-$ Galactosyltransferase $\beta 3$ Gal-T5 acts on the GlcNAc $\beta 1->3 G a l \beta 1-$ $>4 \mathrm{GlcNAc} \beta 1->\mathrm{R}$ sugar chains of carcinoembryonic antigen and other N-linked glycoproteins and is down-regulated in colon adenocarcinomas. J Biol. Chem. 2001, 276, 3564-3573. [CrossRef]

38. Weinstein, J.; Lee, E.U.; McEntee, K.; Lai, P.H.; Paulson, J.C. Primary structure of $\beta$-galactoside $\alpha$ 2,6-sialyltransferase. Conversion of membrane-bound enzyme to soluble forms by cleavage of the $\mathrm{NH}_{2}$-terminal signal anchor. J. Biol. Chem. 1987, 262, 17735-17743. [CrossRef]

39. Takashima, S.; Tsuji, S.; Tsujimoto, M. Characterization of the Second Type of Human $\beta$-Galactoside $\alpha 2$,6-Sialyltransferase (ST6Gal II), Which Sialylates Gal $\beta 1,4$ GlcNAc Structures on Oligosaccharides Preferentially. Genomic Analysis of Human Sialyltransferase Genes. J Biol. Chem. 2002, 277, 45719-45728. [CrossRef]

40. Dall'Olio, F.; Malagolini, N.; Di Stefano, G.; Minni, F.; Marrano, D.; Serafini-Cessi, F. Increased CMP-NeuAc:Gal $\beta 1,4 G l c N A c-R ~ \alpha$ 2,6 sialyltransferase activity in human colorectal cancer tissues. Int. J. Cancer 1989, 44, 434-439.

41. Lise, M.; Belluco, C.; Perera, S.P.; Patel, R.; Thomas, P.; Ganguly, A. Clinical correlations of $\alpha 2,6$-sialyltransferase expression in colorectal cancer patients. Hybridoma 2000, 19, 281-286. [CrossRef] [PubMed]

42. Venturi, G.; Gomes, F.I.; Pucci, M.; Ferracin, M.; Malagolini, N.; Chiricolo, M.; Dall'Olio, F. Impact of sialyltransferase ST6GAL1 overexpression on different colon cancer cell types. Glycobiology 2019, 29, 684-695. [CrossRef] [PubMed]

43. Mito, A.; Kumazawa-Inoue, K.; Kojima-Aikawa, K. ZG16p, an Animal Homologue of Plant beta-Prism Fold Lectins: Purification Methods of Natural and Recombinant ZG16p and Inhibition Assay of Cancer Cell Growth Using ZG16p. Methods Mol. Biol. 2020, 2132, 339-347. [CrossRef]

44. Pattison, A.M.; Merlino, D.J.; Blomain, E.S.; Waldman, S.A. Guanylyl cyclase C signaling axis and colon cancer prevention. World J. Gastroenterol. 2016, 22, 8070-8077. [CrossRef] [PubMed]

45. Low, E.N.D.; Mokhtar, N.M.; Wong, Z.; Raja Ali, R.A. Colonic Mucosal Transcriptomic Changes in Patients with Long-Duration Ulcerative Colitis Revealed Colitis-Associated Cancer Pathways. J. Crohns. Colitis. 2019, 13, 755-763. [CrossRef] [PubMed]

46. Grimmer, M.R.; Costello, J.F. Cancer: Oncogene brought into the loop. Nature 2016, 529, 34-35. [CrossRef] 